\section{Masterly inactivity: A forgotten precept}

To the Editor: When I was a medical student at the University of Cape Town, South Africa, in the mid-1950s a wise old professor introduced me to the treatment concept of masterly inactivity. Sometimes just waiting and seemingly doing nothing is the favoured therapeutic modality. Over a lifetime in medicine, I have seen many occasions when this approach was successful, and other times when physicians, including myself, have broken this rule with unfortunate and antitherapeutic results.

For many years, I practised inpatient and outpatient liaison psychiatry. I used to joke, perhaps a little cynically and certainly with exaggeration, that I got most of my therapeutic successes by stopping rather than prescribing psychotropic medications. This happened especially when a patient had been prescribed two or more psychotropic drugs the combined adverse effects of which were more unpleasant than the symptoms of the original illness.

For the past ten years I have worked in the income security programmes of the federal government of Canada, appraising the applications of Canadians who apply for disability pensions and deciding on their eligibility. This task involves a detailed review of medical reports and files that often extend over many years. It provides a unique chronological perspective of each patient's long-term medical history. I must admit that on many occasions I shake my head sadly when I see a physician ordering yet another magnetic resonance imaging scan or carrying out yet another medical procedure that will not have a meaningful or useful outcome. Often this approach will reinforce a patient's illness behaviour and cost overstretched healthcare systems additional needless dollars. I believe that our patients and our society pay a huge price for this shortsighted approach.

Why do doctors do this? There are several explanations. We have all been taught to practise defensive medicine. If you don't carry out a test or do a procedure, and the patient sues, you could be in legal trouble. Other than to follow sound clinical judgement and evidencebased guidelines, there is no easy answer to this society-imposed measure.

In addition, many patients demand that something, anything, be done to ease their complaint. They believe that action, any action, is better than waiting for the body's built-in remedies to do their bit.

Managing the exigent patient requires tact, information and expertise. Perhaps this is where the word 'masterly' registers. 'Inactivity' does not mean doing nothing. Our bodies have many natural resources for coping with and counteracting disease processes, both physiological and psychological. Waiting can promote these healing resources; by waiting, the doctor becomes a collaborator rather than an adversary competing with the body's natural defences. This is particularly the case with use of antibiotics. Waiting a few days gives time for the immunological defences to be provoked that may make antibiotics unnecessary. These ideas must be conveyed to the patient in a way that he or she can understand.

The fear of missing a treatable organic disease is ingrained during our training and may be another explanation as to why we have forgotten the masterly inactivity precept. To counteract this attitude, we need an equally ingrained fear of perpetuating illness behaviour by ordering unnecessary tests or carrying out poorly indicated medical procedures. This is not to say that an investigation or a test should not be done when there is a clear indication, or when the likelihood of discovering useful information or achieving success is high, or the need is urgent. To delay the diagnosis of breast cancer, for example, is not going to improve the patient's prospects.

The Choosing Wisely Canada initiative (www.choosingwiselycanada.org) fits with this approach to patient management. It makes specific recommendations about the use of antibiotics for respiratory illness in children, for example, or about the use of imaging tests in back pain

In my personal life, I have noticed how some of my medical problems, such as pain from my arthritic knees, improve if I wait a few days or weeks. I was actually able to cancel an arthroscopy that had been recommended by my physician. Perhaps, after all, there is an upside to having long waiting times for certain procedures.

Physicians are counselled to 'First do no harm. In our actioninspired society I sometimes wonder if we have not thrown out the 'nature healing' baby with the 'do something' bath water.

Acknowledgements. Reprinted from F Mai, 'Masterly inactivity: a forgotten precept', Canadian Medical Association Journal 2014;186(4):312. (c) Canadian Medical Association 2014. This work is protected by copyright and the making of this copy was with the permission of the Canadian Medical Association Journal (www.cmaj.ca). Any alteration of its content or further copying in any form whatsoever is strictly prohibited unless otherwise permitted by law. The Royalty Fee has been waived.

\section{François Mai}

Adjunct Professor, Department of Psychiatry, Faculty of Medicine, Queen's University, Kingston, Canada maifse@gmail.com

S Afr Med J 2015;105(4):332. DOI:10.7196/SAMJ.9303 